
H A R V A R D
B U S I N E S S
S C H O O L

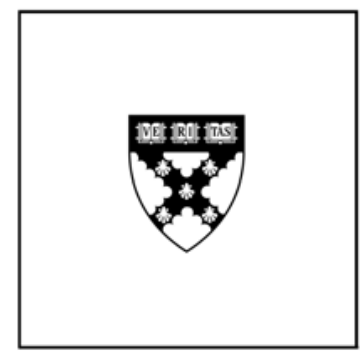

\title{
Location Choices under Strategic Interactions
}

\author{
Juan Alcacer \\ Minyuan Zhao \\ Cristian Dezső
}

\section{Working Paper}

12-104

May 24, 2012 


\title{
Location Choices under Strategic Interactions
}

\begin{abstract}
The literature on location choices has mostly emphasized the impact of location and firm characteristics. However, most industries with a significant presence of multi-location firms are oligopolistic in nature, which suggests that strategic interaction among firms plays an important role in firms' decision-making processes. This paper explores how strategic interaction among competitors affects firms' geographic expansion across time and markets. Specifically, we build a model in which two firms that differ in their capabilities enter sequentially into two markets with different potentials for profit. The model is solved using game theory under three learning scenarios that capture the ability of a firm to transfer its capabilities across markets: no learning, local learning, and global learning. Three equilibrium strategies arise: accommodate, marginalize, and collocate. We identify how these strategies emerge depending on the tradeoff between the opportunity costs of absence (giving competitors a lead in a market) and the entrenchment benefits (the cost advantage firms develop through learning-by-doing when they enter early). Both the opportunity costs of absence and the entrenchment benefits vary according to initial relative firm capabilities, relative market profitability, and learning rates. Our model offers a comprehensive approach to understanding the drivers of firm location choices by modeling not only the impact of location and firm heterogeneity, but also the strategic interaction among firms.
\end{abstract}

KEYWORDS: location strategies, multinational strategy, oligopolistic competition, game theory, firm heterogeneity 


\section{Introduction}

What determines firms' location choices when expanding geographically? A vast literature has emphasized the impact of location traits (Caves, 1996; Coughlin, Terza, \& Arromdee , 1991) and, to a lesser extent, firm traits (Shaver \& Flyer, 2001; Alcacer \& Chung, 2010) on location choices. Nevertheless, recent anecdotal evidence suggests there are differences between firms' geographic expansion strategies, in terms of timing and location selection, that are richer and more complex than the current literature reflects. For example, some firms prefer peripheral markets and postpone entry to attractive markets until they develop capabilities to defy incumbents. Wal-Mart initially favored rural markets where it was easier to drive out weaker competitors and deter potential entrants; only later did it begin competing directly in areas where K-mart was incumbent. Similarly, multinational enterprises (MNEs) may vary their strategy by country depending on the competitors they expect to face. Cellular leaders Nokia and Ericsson chased weaker competitors in European markets while gracefully avoiding each other in their international expansions. These examples suggest that firms not only react to location traits, but also make location decisions strategically across time and markets to enhance and protect their relative competitive positions, factoring in their rivals' present and future location choices. A geographic diversification strategy thus resembles a chess game: each move depends not only on the board — an array of potential locations - but also on the pieces in play - firm heterogeneity - and on the interaction between players - strategic interaction. Exploring location choices without including all three components misses key elements of the game.

This paper enhances our understanding of firms' location decisions by exploring how strategic interaction across time and markets influences location strategies, while accounting for location attractiveness and firm heterogeneity. When firms expand into new geographic markets, they have a vast set of common options from which to choose. But entering a new market requires resources, so firms are limited in the number of markets they can enter simultaneously in a given period of time. In effect, a firm that chooses one new geographic market is also postponing entry into other potential markets, giving 
competitors lead-time to improve their competitive positions in those markets. This tradeoff-between the benefits of entering and the opportunity costs of postponing - determines whether firms will choose a location strategy that avoids competitors or one that collocates with them.

We explore the circumstances under which firms collocate or avoid each other using a game-theoretic model in which heterogeneous firms choose to enter new geographic markets across time, taking their competitors and their competitors' locations into account. Specifically, the model examines how (1) heterogeneity between locations (market attractiveness), and (2) heterogeneity between firms (relative firm capabilities and learning rates from local markets) change (3) the benefit of entering one market and the opportunity cost of postponing entry to another market. In the chess analogy, these three factors account for the board, the pieces at play, and the strategic interaction between players.

As in any attempt to formalize a complex phenomenon, we face a tradeoff between narrow richnesstaking few elements that are fully characterized—and comprehensive simplicity—including all elements but in a stylized manner. We opted for the latter. We condense the many dimensions of location heterogeneity into market value, which is common to all firms. We model firm heterogeneity through initial competitive positions represented by the share of market value a firm can capture. We model strategic interaction based on knowledge creation and diffusion —-learning across locations among few players and on a limited time horizon. Moreover, we model only two aspects of knowledge diffusion that affect strategic interaction: its speed —-through learning rates — and its scope — through global learning and local learning scenarios.

Clearly, this approach misses some of the richness present in competitive landscapes: locations vary in more than their potential value; competitors differ along many dimensions; strategic interaction may be triggered by parameters beyond learning; competitors may be numerous; and learning is more than a multidimensional phenomenon. However, we believe that in spite of its simplicity, our model captures the essential aspects of the context we are studying, and more importantly, it offers a comprehensive approach to understanding the drivers of firm location choices by modeling not only the impact of 
location and firm heterogeneity, but also the strategic interaction between firms. In essence, our purpose is not to understand every particular competitive situation that firms might face when expanding geographically, but rather to highlight the general direction of the effect of strategic interaction on firms' location choices.

This approach enriches the location literature in several ways. First, it revives a focus on the impact of strategic interaction on firms' location decisions, a core idea in the seminal works of Knickerbroker (1973) and Hymer (1976) in global strategy. Second, it incorporates the use of basic game-theoretic modeling tools from industrial organization to address a strategy question. Third, although our primary focus is expansion in geographic space, our model can be extended to expansion in the product space. Fourth, it contributes to the nascent economic geography literature that focuses on competitive models and location choices (Ellickson and Zame, 2005).

The next section reviews the relevant literature, summarizes the model, explains its assumptions and predictions, and introduces the intuition behind them. Section 3 describes the model and frames the analysis in terms of collocation across markets. We establish the baseline results for three equilibrium location strategies - accommodate, marginalize, and collocate - from the no-learning scenario in Section 3.1. In sections 3.2 and 3.3, we explore the local and global learning scenarios emphasizing the concepts of entrenchment benefits and opportunity costs, and illustrate the effects of different learning rates on the three basic location strategies. Finally, we discuss the limitations of this approach in Section 5, after we summarize our findings and their implications.

\section{Strategic Interaction and Location Strategies}

Previous research in economic geography on location decisions falls into two broad categories: endowment-driven and agglomeration-driven. The first stream of literature draws on traditional trade theory and argues that industries concentrate in regions with appropriate factor endowments. A broad view of factor endowments would include location traits such as physical infrastructure, labor force quality, and cultural distance (Coughlin, Terza, \& Arromdee, 1991; Flores and Aguilera, 2007) and, in 
more recent studies, institutional features such as political risk (Henisz, 2000) and the enforcement of property rights (Lee \& Mansfield, 1996). In this literature, firms (incumbent or potential entrants) play a minimal role in attracting or deterring entry by competing firms.

The agglomeration perspective began with the seminal work by Marshall (1892), which established three mechanisms that yield positive externalities to firms that geographically cluster: inter-firm technological spillovers, access to specialized labor, and access to specialized intermediate inputs. These agglomeration economies have since been incorporated in formal models (e.g., David 1990; Krugman 1991) and empirically supported in local (Carlton, 1983) and international settings (Wheeler \& Mody 1992; Head et al. 1995). Although this literature argues that the presence of other firms attracts new entrants, its unit of analysis is typically a specific location rather than the strategic moves made by firms (which may span multiple locations). It is also silent about the strategic interactions among firms that may lead to lower profits.

Whether based on endowments or on agglomeration, these theories of location predict that firms in the same industry cluster geographically. However, most of these models, and particularly those in the agglomeration literature, assume that markets are competitive and firms are homogeneous, or that firms are small relative to industry output and therefore have no noticeable effect on factor prices or agglomeration externalities. Krugman (1991) expresses the need to move beyond perfect competition assumptions when he writes:

"Essentially, to say anything useful or interesting about the location of economic activity in space, it is necessary to get away from the constantreturns, perfect competition approach that still dominates most economic analysis."

Perfect competition among homogenous firms is hardly true for most firms expanding geographically, particularly among multinational enterprises (MNEs). The determinants that give rise to MNEs, e.g., proprietary assets that make them unique (Caves, 1996), are also more likely to lead to oligopolistic industries. The difference between oligopoly and perfect competition is vividly illustrated by $\mathrm{Yu}$ and Ito 
(1998), who find that firms' motivation to engage in foreign direct investment (FDI) is affected by their rivals' moves in the oligopolistic tire industry but not in the competitive textile industry.

Location decisions are naturally more complex when markets are less-than-perfectly competitive and when firms are heterogeneous. Locating close to competitors can increase competitive pressure to levels that hinder any benefit from clustering. For example, Shaver and Flyer (2001) argued that firms might shy away from clusters if their contributions to agglomeration economies might exceed the potential benefits obtained by clustering. Alcacer and Chung (2010) extended this argument for specific sources of agglomeration economies — specialized labor, specialized suppliers, and knowledge spillovers—by highlighting that firms react differently to each agglomeration benefit. These papers provide evidence that strategic interaction — how firms' actions depend on their competitors' actions — play a role on location choices.

However, strategic interaction does not always translate into the competition and deterrence these papers suggest. The multimarket contact literature suggests that firms enter the same markets as competitors to soften competition. For instance, Gimeno et al. (2005) find that firms competing in the domestic market tend to follow each other to the same foreign markets, while non-competing firms try to avoid each other geographically when pursuing internationalization strategies. Lieberman and Asaba (2006) summarized that rival firms may follow each other into markets to constrain competition and maintain tacit collusion, or to maintain their relative competitive positions and minimize competition risks. Similarly, Ghemwat \& Thomas (2008) suggest that global firms in the cement industry collocate across markets to support collusion in prices. In addition, Yu et al. (2008) show that not only does the competitive aggressiveness of MNE subsidiaries decline as multimarket contact increases, the effect is stronger when those MNEs have greater ownership (and hence higher influence) in their subsidiaries.

Both literature streams, strategic agglomeration and multimarket contact, move beyond location per se as the unit of analysis to view locations as a rich and critical context in which firms compete. Thus, on top of location traits, these papers suggest that the presence (or absence) of firms will add to (or subtract 
from) a location's perceived value, which will in turn drive strategic location choices. Under this view, firms may alter the underlying attractiveness of a location with their presence: sometimes they become a centripetal force, attracting more firms through agglomeration economies or collusion agreements; sometimes they become a centrifugal force, repelling firms by increasing competition for production factors or product markets. In either case, our understanding of location choices and their strategic value to firms would not be complete without incorporating strategic interaction.

Fortunately, industrial organization (IO) has made important advances in modeling strategic interaction among firms (the set of actions a firm undertakes to limit rivals' choices) in the oligopolistic industries where MNEs typically compete (Berry, 1992; Bresnahan \& Reiss, 1991). This research argues that firms evaluating strategic decisions will try to anticipate how their competitors will react. Given that the research in strategy — particularly in FDI—and IO both deal with oligopolistic industries, one might be surprised by the sparseness of recent research applying IO concepts and tools, such as game theory or multimarket contact, to explain MNE location choices. This is particularly surprising given that seminal papers in FDI drew heavily on industrial organization (Knickerbrocker, 1973; Hymer, 1976; Yu \& Ito, 1988). The small literature that does use strategic interaction to explain MNEs' location behavior is promising. Veugelers (1995) introduced a game-theoretic model that shows when strategic considerations may dominate and possibly counteract firms' traditional motives for moving abroad, such as locational and firm-specific advantages. Using a non-cooperative game, Graham (1998) concluded that it is neither necessary nor sufficient that a firm have lower costs than its rivals in order to have an incentive to become an MNE. Of course, while these papers incorporate strategic interaction to explain MNEs' behavior, their goal is to explain firms' incentives to become MNEs rather than to explain subsequent location decisions.

Our objective is to explore how strategic interaction affects the geographic expansion of heterogeneous firms across time and markets. The game-theoretic model we employ is designed to capture the dynamics of oligopolistic industries that emerge around a product with a potential worldwide market. In this context, fast global expansion is desirable and selecting locations across countries becomes 
critical not only because it increases profits, but because it may deter competitors from entering and entrenching in key markets.

Specifically, we build a model in which two firms with different capabilities enter sequentially into two markets with different potentials for profit. Firms learn by operating in a market, and learning increases capabilities, which we equate with cost reduction. In that sense, learning is also associated with the scale of production and hence the market share a firm obtains: the larger the market share, the more the firm learns and the more it improves its capabilities. This relationship is grounded in the wellaccepted and tested models of learning-by-doing (Eppel, Argote, \& Rukmini, 1991). For a given market, a firm learns more when it is a monopolist than when it collocates with a competitor. Therefore, a firm can improve its relative competitive position by learning more (reducing costs more) than its competitors. In other words, learning is the mechanism that links capabilities and location decisions across time and that may change the initial capability gap between firms.

The model is solved using the traditional game theory concept of sub-game perfect equilibrium under three separate learning scenarios: no learning, local learning, and global learning. These scenarios capture the ability of a firm to transfer its capabilities across markets. With no learning (our baseline scenario), firms keep their initial capability level across time. With local learning, capabilities are location-specific and are not transferrable across locations. With global learning, firms can duplicate capabilities gained in one market in other markets. ${ }^{1}$

Three equilibrium strategies emerge from the model: accommodate, marginalize, and collocate. We identify how these strategies are likely to emerge depending on three parameters: initial relative firm capabilities, relative market profitability, and learning rates. In discussing these location strategies we pay

\footnotetext{
${ }^{1}$ The local-learning and global-learning scenarios can be mapped to the typology of multinational firms developed by Bartlett \& Ghoshal (1989), in which local learning is more likely to emerge from multinational strategies and global learning is more likely to emerge from transnational strategies.
} 
special attention to two dimensions: dynamic collocation (whether firms collocate or avoid each other in the first period) and aggressiveness (whether a firm enters the highest-value market first).

In general, the model suggests that firms will avoid each other initially and collocate later when firms or markets are similar. Accommodate and marginalize are avoidance strategies that emerge depending on whether a firm chooses a core market (more attractive) or a peripheral market (less attractive) first. In a marginalize strategy, the more capable firm initially relegates the less capable firm to a peripheral market when the gap between their relative capabilities is large or when the peripheral market is distinctly less attractive. As the value of the peripheral market increases and approaches that of the core market, and as the firms become more similar, a new avoidance strategy emerges: accommodate. Under the accommodate strategy, the more capable firm momentarily cedes the core market to its competitor; the competitor obtains monopoly rents in the core market while the more capable firm keeps monopoly rents in the peripheral market. The third equilibrium strategy, collocate, emerges when the peripheral market is small (increasing the core market's attractiveness even when it is shared by a competitor). In this case, the firms enter markets contemporaneously.

With learning, two forces that drive location strategies emerge: the opportunity cost of not entering a market and the entrenchment benefit of entering early. Learning introduces the opportunity cost of not entering a market because it allows a competitor to learn and improve its competitive position. As a result, a firm is driven not only by its initial firm capabilities and relative market sizes, but also by the need to preserve, improve, or minimize the erosion of its relative competitive position over time due to competitors' learning processes. How effective firms are at this task depends on their rate and type of learning.

The opportunity cost of not entering a market will increase as firms learn more and when they transfer new knowledge across markets. For example, when either type of learning occurs, we will most often see the more capable firm become more aggressive and enter the core market first, favoring a marginalize strategy instead of an accommodate strategy. In this case, the opportunity cost of not entering the core 
market would increase because the less capable firm would have more room to learn, improve its capabilities, and reduce its competitive gap. The larger the learning rate, the more aggressive the more capable firm becomes (because less capable firm can catch up more easily) and the more likely a marginalize strategy emerges. The trend towards the marginalize strategy is stronger in a global learning scenario than in a local learning scenario because firms can transfer learning advantages across locations, affecting their cross-market competitive positions.

Although the less capable firm also experiences opportunity costs, whether those costs trigger aggressiveness depends on relative market size. When both markets are of similar size, the less capable firm is inclined to locate in the peripheral market - e.g., becoming less aggressive and supporting a marginalize strategy—so that it can learn more and improve its competitive position. Locating early in a peripheral market can improve a firm's competitive advantage by offering an entrenchment benefit similar to a traditional first-mover advantage. This entrenchment benefit will be stronger when learning is local. Only when the core market is much more attractive, and learning opportunities are tepid in the peripheral market, will the less capable firm favor a collocate or accommodate strategy by aggressively moving to the main market.

\section{The Model}

To trace the effect of strategic interactions on location choices, we consider a two-period model where two firms, $i=h, l$, decide to expand sequentially in two markets, $j=H, L .^{2}$ The markets differ in the potential value appropriable by firms - i.e., 'the size of the pie' — denoted by $V^{j}$, and we consider that $V^{L}=\gamma V^{H}$, where $\gamma \in[0,1]$. For example, when $\gamma$ is equal to 0.5 , the potential profits in the low-value market, $V^{L}$, are half of those in the high-value market, $V^{H}$.

We assume that firms expand to one location per period. Restricting entry to no more than one country is sensible because transferring technology into new markets is difficult, managers are limited in

\footnotetext{
${ }^{2}$ For firms, $h$ and $l$ stand for high-capability and low-capability, as defined later in the text. For markets, $H$ and $L$ stand for high-value and low-value potential profits.
} 
their capacity to supervise simultaneous expansions, and financial resources for concurrently opening operations may not be available. Thus, firm $i$ 's strategy, $s_{i}$, is defined as a tuple $s_{i}=s_{i t} \mid t=1$, 2 , where $s_{i t}$ represents firm $i$ 's market presence in period $t$, with $s_{i t} \in\{(\varnothing, \varnothing),(L, \varnothing),(\varnothing, H),(L, H)\}$. For example, if firm $l$ enters market $H$ in period 1 and enters market $L$ in period 2, we write the firm's strategy as $s_{l}=\{(\varnothing, H),(L, H)\}$

Firms choose strategies that maximize their profits considering rivals' moves. Per-period gross profits are denoted by $\pi_{i t}$, so that total profit for firm $i$ across time is $\Pi_{i}=\pi_{i 1}+\pi_{i 2} \cdot{ }^{34}$ A firm that enjoys a monopolistic position in market $j$ receives gross profits equal to $V^{j}$; for example $\pi_{h 1}=V^{L}$ if firm $h$ is a monopolist in market $L$ in the first period. ${ }^{5}$

We introduce firm heterogeneity through differences in firms' endowments of initial capabilities to produce and sell in markets. Any strategic advantage in capabilities that a firm has over its competitors (e.g., better management, higher efficiency, product quality, etc.) is reflected in larger gross profits and market share. Let $\alpha_{j t}$ be the share of total market value that firm $l$ captures in a market $j$ in period $t$ in which it competes with firm $h$. If in period $t$ both firms are in market $j$, gross profits for firm $l$ and $h$ are $\pi_{l t}=\alpha_{j t} V^{j}$ and $\pi_{h t}=\left(1-\alpha_{j t}\right) V^{j}$ respectively. ${ }^{6}$ Thus $\alpha_{j t}$ represents the relative capability of firm $l$ with respect to firm $h$. We assume that $\alpha_{j t}<1 / 2$, that is, that firm $l$ is less capable in the first period, since the other case $\left(\alpha_{j t}>1 / 2\right)$ is symmetrical. By using $\alpha_{j t}$ as a parameter to capture profits under

${ }^{3}$ Presence in a market involves a fixed cost per period $K$. We assume that $K$ is small enough that firms can have positive duopolistic profits in any country. We make this assumption partly because we consider oligopolistic industries with sufficiently large firms that are likely to be able to afford their fixed costs, but also because it helps keep the model tractable and makes its predictions easier to understand.

${ }^{4} \mathrm{We}$ are aware of the discount factor missing from this equation. Adding a discount rate to $\pi_{i 2}$ makes the model more complicated but does not qualitatively change the result.

${ }^{5}$ We are aware that appropriability varies by firm. While the more capable firm would capture $V^{j}$, the less capable firm would capture $V^{j}-f(c)$. This differential treatment only changes the boundary conditions (shifting the lines in figures 1-4) but not the mechanics of our findings. We opted for simplicity: setting $f(c)$ equal to 0 instead of cluttering the model with an extra parameter that does not impact the model's foundational intuition.

${ }^{6}$ When $\alpha_{j t}<1 / 2$, firm $l$ is less capable than firm $h$ and, as a consequence, $\pi_{l t}<\pi_{h t}$ in market j; when $\alpha_{j t}>1 / 2$, firm $h$ is the one with lower capability endowments, lower potential gross profit, and lower market share. 
oligopoly, we do not make any specific assumption about the mode of competition (i.e., Bertrand, Cournot, Hotelling, etc.) between the two firms in market $j$ at time $t$, producing a less constrained model.

Following previous work in economics (Spencer, 1981) and management (Eppel, Argote, \& Rukmini, 1991), we assume that firms learn from experience. As firms become familiar with the production process in a new market, identify the best suppliers there, develop working routines, and adapt their technology to market conditions and regulations, they are able to improve their absolute competitive position. Learning introduces dynamic firm capabilities and offers a more realistic representation of actual firm behavior. We assume that the learning rate is $\lambda$ for both firms, with $\lambda \in[0,1]$.

Although learning-by-doing improves a firm's absolute capabilities, its effect on relative capabilities is unclear until the rival's learning process is also accounted for. Through its entry decisions, a firm can maintain or improve its relative competitive position by indirectly affecting its rival's output and its learning process. Let $\alpha_{j 2}^{S}$ denote firm $l$ 's second-period relative capability in market $j$ when firms follow strategy $s$ at time $t=1$. For example, when more capable firm $h$ enters high-value market $H$, and less capable firm $l$ enters low-value market $L$, the resulting second-period relative capability is $\alpha_{j 2}^{H L}$; when both firms enter the high-value market at time $t=1$, second-period relative capability is $\alpha_{j 2}^{H H}$. The learning process is the key element in the model that links location decisions across time.

The model encompasses three learning scenarios that differ in whether and how relative capability $\left(\alpha_{j t}\right)$ changes over time: no learning (firms' absolute capabilities are static and identical across countries), global learning (the firm's cumulative experience improves its second-period absolute capability across all markets), and local learning (the cumulative experience gained by a firm in one market improves its second-period absolute capability only in that market). 
Regardless of the learning scenario, we use sub-game perfect Nash equilibrium (SGPNE) to identify the strategies that maximize the profits for both firms. To avoid the issue of mixed strategies, we assume sequential entry ${ }^{7}$ with the less capable firm being first to make an expansion decision. ${ }^{8}$

\section{No-learning scenario}

Under the no-learning scenario, firms' absolute and relative capabilities do not depend on their firstperiod strategies and are static across time and markets $\left(\alpha_{j 2}^{S}=\alpha_{j 2}^{H L}=\alpha_{j 2}^{H H}=\alpha_{j 2}^{L H}=\alpha_{1}, \forall j=L, H\right)$. Similarly, firms' second-period strategies $\left(s_{i 2}\right)$ and payoffs $\left(\pi_{i 2}\right)$ do not depend on first-period strategies. Consequently, we identify equilibrium strategies comparing only first-period strategies and payoffs. As already mentioned, we consider that both firms are profitable in both markets (see footnote 3 ).

Assume that the less capable firm $l$ chooses high-value market $H$ in the first period (strategy $s_{l 1}=$ $(\emptyset, H))$. More capable firm $h$ can either avoid firm $l$ by entering low-value market $L$ (strategy, $s_{h 1}=$ $(L, \emptyset)$, with associated profit $\left.\pi_{h 1}=V^{L}\right)$, or collocate with firm $l$ by entering the high-value market (strategy, $s_{h 1}=(\varnothing, H)$, with associated profit $\left.\pi_{h 1}=\left(1-\alpha_{1}\right) V^{H}\right)$. Firm $h$ will avoid firm $l$ when its benefit from being a monopolist in the low-value market, $V^{L}$ is greater than its benefit from sharing the high-value market, $\left(1-\alpha_{1}\right) V^{H}$, that is when

$$
\gamma>\left(1-\alpha_{1}\right)
$$

If however $N L-1$ does not hold, firm $h$ expands in the high-value market in the first period. In this case, the less capable firm $l$ chooses between avoiding firm $h$ and entering the low-value market $L$ (strategy $s_{l 1}=(L, \varnothing)$, with associated profits $\pi_{l 1}=V^{L}$ ), or collocating with firm $h$ in the high-value

\footnotetext{
${ }^{7}$ We favor sequential entry over simultaneous entry for multiple reasons. First, sequential entry provides strategies in which it is easier to isolate the effect of the model parameters on location choices. Simultaneous entry introduces mixed strategies that add complexity of exposition but do not change the model's main insights. Second, our motivating examples (Wal-Mart vs. K-mart; Nokia and Ericsson) seem to suggest sequential entries. Third, sequential entry is often assumed in deterrence models. Our model falls within this category in that incumbents deter entrants by lowering costs through learning instead of through overinvestment in capacity, which could trigger price wars if entry occurs.

${ }^{8}$ Assuming that the more capable firm moves first would lead to the trivial result in which it always expands in the high-profit market, regardless of its rival's strategy.
} 
market $\mathrm{H}$ (strategy $s_{l 1}=(\varnothing, H)$, with associated profits $\left.\pi_{l 1}=\alpha_{1} V^{H}\right)$. The less capable firm $l$ will avoid firm $h$ if its benefit from being a monopolist in the low-value market, $V^{L}$, is greater than its benefit from sharing the high-value market, that is, when

$$
\gamma>\alpha_{1}
$$

Three distinctive strategies, summarized in Table 1, emerge as equilibria depending on whether conditions $N L-1$ and $N L-2$ hold. When neither condition holds $\left(\gamma<\alpha_{1}<\left(1-\alpha_{1}\right)\right)$, firms will collocate sequentially. This strategy, collocate, corresponds to $s_{h}=\{(\varnothing, H),(L, H)\}$ and $s_{l}=\{(\varnothing, H),(L, H)\}$. The other two strategies involve mutual avoidance during the first period and differ in whether firm $h$ targets the high-value market initially. When conditions $N L-1$ and $N L-2$ hold $\left(\alpha_{1}<\left(1-\alpha_{1}\right)<\gamma\right)$, the more capable firm, $h$, concedes the high-value market in the first period to firm $l$. Anticipating firm $h$ 's accommodating behavior, firm $l$ will be more aggressive and expand into the high-value market first. This strategy, accommodate, corresponds to $s_{h}=\{(L, \varnothing),(L, H)\}$ and $s_{l}=\{(\emptyset, H),(L, H)\}$. If only condition (NL-1) is violated $\left(\alpha_{1}<\gamma<\left(1-\alpha_{1}\right)\right)$, firm $h$ acts more aggressively by marginalizing firm $l$ to the lowvalue market, even though firm $l$ is the first to expand. Firm $l$ is less aggressive in its behavior and concedes the high-value market to firm $l$. This strategy, marginalize, corresponds to $s_{h}=\{(\varnothing, H),(L, H)\}$ and $s_{l}=\{(L, \varnothing),(L, H)\}$.

Table 1: Equilibrium Strategies. No-learning equilibrium, no exit

\begin{tabular}{|c|c|c|}
\hline Parameters & Strategy & Type \\
\hline$\left(1-\alpha_{1}\right)<\gamma$ & $s_{h}=\{(L, \varnothing),(L, H)\}$ & Accommodate \\
& $s_{l}=\{(\varnothing, H),(L, H)\}$ & \\
\hline$\alpha_{1}<\gamma<\left(1-\alpha_{1}\right)$ & $s_{h}=\{(\varnothing, H),(L, H)\}$ & Marginalize \\
& $s_{l}=\{(L, \varnothing),(L, H)\}$ & \\
\hline$\gamma<\alpha_{1}$ & $s_{h}=\{(\varnothing, H),(L, H)\}$ & Collocate \\
& $s_{l}=\{(\varnothing, H),(L, H)\}$ & \\
\hline
\end{tabular}


These results are intuitive. If markets are of similar profitability (if $\gamma$ is approaching 1), and firms are of similar capability (if $\alpha_{1}$ is approaching 1/2), then firms will avoid each other. The more capable firm $h$ will adopt an accommodate strategy, as the opportunity cost of not competing with a strong competitor in a slightly more valuable market is lower than the benefit of being a monopolist in a slightly less valuable market. Both conditions, similar market value and similar firm capabilities, reduce firm $h$ 's opportunity costs from not locating in the high-value market early on. As market profitability and/or capability differentials increase, that is, when $\gamma$ and/or $\alpha_{1}$ decrease, firm $h$ 's opportunity cost from not locating first in the high-value market increases. As a result, firm $h$ becomes more aggressive and tries to hamper firm $l$ from entering the market. If market values are not too dissimilar (if $\gamma$ is not too small), or if firms are of dissimilar capabilities (if $\alpha_{1}$ is approaching 0 ), this marginalize strategy is successful: firm will avoid each other in the first period, with the less capable firm confined to a less attractive and peripheral market and the more capable firm enjoying monopoly power in a more valuable core market. Finally, even when firm $h$ is more aggressive, if market profitability differentials are large enough (if $\gamma$ is approaching 0 ), or if firms are of similar capabilities (if $\alpha_{1}$ is approaching $1 / 2$ ), firm l's opportunity costs from not locating in the high-value market early on increase. As a result, firm $l$ will become more aggressive and will collocate with firm $h$ in the first period. Note that in the absence of learning, strategic decisions do not depend on preserving or improving a firm's relative competitive position.

Figure 1: Equilibrium strategies: no-learning scenario.

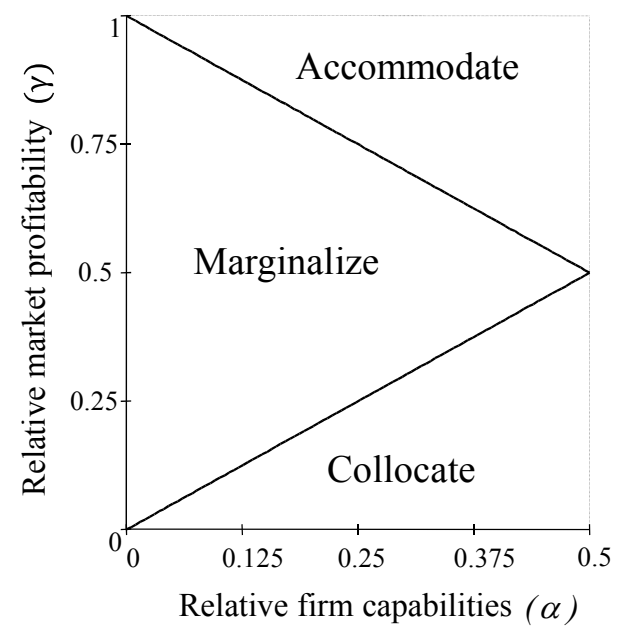


Figure 1 shows the equilibria areas determined by equations $N L-1$ and $N L-2$. Note that, in terms of collocation, for a fixed capability differential $\alpha$, an increase in the profitability differential of the two markets (a decrease in $\gamma$ ) increases the likelihood of collocation. For a fixed profitability differential $\gamma$, an increase in the capability differential (a decrease in $\alpha_{1}$ ) decreases the likelihood of collocation.

\section{Global learning}

Under the global learning scenario, the first-period experience gained by firm $i$ in market $j$ improves its second-period absolute capability, equalizing it across both markets. However, this improvement is dependent on first-period strategies, so that $\alpha_{j 2}^{H L} \neq \alpha_{j 2}^{L H} \neq \alpha_{j 2}^{H H} \neq \alpha_{1}, \forall j=L, H$, and for a given strategy $s$, $\alpha_{L 2}^{S}=\alpha_{H 2}^{S}=\alpha_{2}^{S}$. Thus, in contrast to the no-learning scenario, identifying equilibrium strategies requires comparing profits obtained in both periods.

We solve this game by backward induction. Thus, we assume, first, that firm $l$ enters the high-value market in the first period (strategy $s_{l 1}=(\emptyset, H)$ ). Then, the more capable firm $h$ must decide whether to avoid and accommodate the less capable firm $l$ (strategy $s_{h 1}=(L, \emptyset)$ ) or collocate with it (strategy $\left.s_{h 1}=(\emptyset, H)\right)$. Table 2 summarizes these two options with the corresponding profits for both firms.

Table 2: Moves for firm $h$ when firm $l$ enters high-value market $H$. Global learning scenario.

\begin{tabular}{|c|l|l|l|}
\hline & Strategies $\mathrm{t}=1$ & Strategies $\mathrm{t}=2$ & \multicolumn{1}{c|}{ Profits $\mathrm{t}=2$} \\
\hline Avoid & $s_{h 1}=(L, \emptyset)$ & $s_{h 2}=(L, H)$ & $\pi_{h 2}=\left(1-\alpha_{2}^{L H}\right)\left(V^{L}+V^{H}\right)$ \\
& $s_{l 1}=(\varnothing, H)$ & $s_{l 2}=(L, H)$ & $\pi_{l 2}=\alpha_{2}^{L H}\left(V^{L}+V^{H}\right)$ \\
\hline Collocate & $s_{h 1}=(\emptyset, H)$ & $s_{h 2}=(L, H)$ & $\pi_{h 2}=\left(1-\alpha_{2}^{H H}\right)\left(V^{L}+V^{H}\right)$ \\
& $s_{l 1}=(\varnothing, H)$ & $s_{l 2}=(L, H)$ & $\pi_{l 2}=\alpha_{2}^{H H}\left(V^{L}+V^{H}\right)$ \\
\hline
\end{tabular}

Firm $h$ 's decision of whether to collocate initially depends on the comparison between its total profits from accommodating firm $l, V^{L}+\left(1-\alpha_{2}^{L H}\right)\left(V^{L}+V^{H}\right)$, and its total profits under sequential collocation, $\left(1-\alpha_{1}\right) V^{H}+\left(1-\alpha_{2}^{H H}\right)\left(V^{L}+V^{H}\right)$. Specifically, firm $h$ avoids and accommodates firm $l$ when 


$$
\gamma>\left(1-\alpha_{1}\right)+\left(\alpha_{2}^{L H}-\alpha_{2}^{H H}\right)(1+\gamma) \quad(G L-1)
$$

Conditions $G L-1$ and $N L-1$ differ only in the term $\left(\alpha_{2}^{L H}-\alpha_{2}^{H H}\right)(1+\gamma)$, which represents firm $h$ 's opportunity cost from letting its rival improve its second-period relative capabilities, as $\alpha_{2}^{L H}>\alpha_{2}^{H H} \cdot{ }^{9}$ The larger the opportunity cost, the more likely is that condition $G L-1$ does not hold, inducing firm $h$ to collocate with firm $l$ in the first period. By collocating early, firm $h$ curbs firm $l$ 's learning and contains the erosion of its second-period relative position. Compared to the no-learning scenario, firm $h$ 's incentives to accommodate firm $l$ decrease and more collocation is expected in the early stages of expansion.

When firm $h$ expands initially into the high-value market, firm l's alternative is to avoid firm $h$ by locating in the low-value market (strategy $s_{l 1}=(L, \emptyset)$ ) or to collocate by entering the high-value market (strategy $s_{l 1}=(\varnothing, H)$ ). Table 3 summarizes these options with the corresponding profits for both firms.

Table 3: Moves for firm $l$ when firm $h$ enters high-value market $H$. Global learning scenario.

\begin{tabular}{|c|l|l|l|}
\hline & Strategies $\mathrm{t}=1$ & Strategies $\mathrm{t}=2$ & \multicolumn{1}{c|}{ Profits $\mathrm{t}=2$} \\
\hline Avoid & $s_{h 1}=(H, \emptyset)$ & $s_{h 2}=(L, H)$ & $\pi_{h 2}=\left(1-\alpha_{2}^{H L}\right)\left(V^{L}+V^{H}\right)$ \\
& $s_{l 1}=(L, \emptyset)$ & $s_{l 2}=(L, H)$ & $\pi_{l 2}=\alpha_{2}^{H L}\left(V^{L}+V^{H}\right)$ \\
\hline Collocate & $s_{h 1}=(\emptyset, H)$ & $s_{h 2}=(L, H)$ & $\pi_{h 2}=\left(1-\alpha_{2}^{H H}\right)\left(V^{L}+V^{H}\right)$ \\
& $s_{l 1}=(\emptyset, H)$ & $s_{l 2}=(L, H)$ & $\pi_{l 2}=\alpha_{2}^{H H}\left(V^{L}+V^{H}\right)$ \\
\hline
\end{tabular}

As before, firm $l$ avoids firm $h$ when the benefit from being a monopolist in the low-value market is greater than the opportunity cost of sharing the high-value market. Specifically, firm $l$ avoids firm $h$ if $V^{L}+\alpha_{2}^{H L}\left(V^{L}+V^{H}\right)>\alpha_{1} V^{H}+\alpha_{2}^{H H}\left(V^{L}+V^{H}\right)$ or alternatively if

$$
\gamma>\alpha_{1}+\left(\alpha_{2}^{H H}-\alpha_{2}^{H L}\right)(1+\gamma)
$$

${ }^{9}$ Our assertion that $\alpha_{2}^{L H}>\alpha_{2}^{H H}$ relies on a simple Cournot model of quantity competition between two firms with different marginal costs, and on the widely accepted idea in the literature on organizational learning, whereby one manifestation of the learning curve is that of marginal costs decreasing with the past quantity produced. In such a model, the quantity produced under monopoly, and thus implicitly the decrease in marginal costs, is larger than the quantity produced by the same firm under oligopoly: Thus, a firm's ability to capture a larger share of profits in a market increases more when it is initially a monopolist, resulting in $\alpha_{2}^{L H}>\alpha_{2}^{H H}$. 
As with $G L-1$, a new term emerges under global learning from firm l's perspective. But in contrast to condition $G L-1$, the sign of this new term is not always positive and depends on the relative profitability of the two markets, $\gamma$. When $\gamma$ is high and the two markets offer relatively similar learning opportunities, firm $l$ can improve its relative position more by being a monopolist in the low-value market than by being a duopolist in the high-value market. Thus, as $\gamma$ increases, $\alpha_{2}^{H H}<\alpha_{2}^{H L}$ and firm $l$ is less aggressive. In this case, the extra term captures an opportunity benefit that allows firm $l$ to catch up with firm $h$. In contrast, for small values of $\gamma, \alpha_{2}^{H H}>\alpha_{2}^{H L}$ and firm $l$ favors being a duopolist in the high-value market instead of a monopolist in the low-value market, because the latter offers fewer opportunities to learn and improve its relative competitive position in the second period. Thus, compared to the no-learning scenario, firm $l$ becomes less aggressive (it collocates less) when markets are not too dissimilar and learning opportunities are more abundant, but becomes more aggressive (it collocates more) when markets are very dissimilar and hamper learning opportunities.

The extra terms in GL-1 and GL-2 introduce a new element in the trade-off between collocation and avoidance that is absent when learning does not occur. With global learning, firms are driven not only by initial firm and market heterogeneity, but also by the need to preserve, improve or minimize the erosion of their relative competitive position over time. For example, firm $h$ collocates to curb its rival's learning process thus avoiding any erosion in its relative competitive position, while firm $l$ chooses between lowand high-value markets to maximize learning and reduce or maintain the capability gap.

More generally, global learning introduces a trade-off between any two strategies, $s$ and $v$, that depends not only on the relative market values $\gamma$, as highlighted above, but also on the speed of learning $\lambda$, so that $\alpha_{2}^{S}-\alpha_{2}^{v}$ can be modeled as a function of these parameters: $\left(\alpha_{2}^{S}-\alpha_{2}^{v}\right)=f(\lambda, \gamma)$. To illustrate how these parameters affect expansion strategies and firms' behavior under global learning, we introduce a functional form for $f(\lambda, \gamma)$ that preserves the intuitive behavior described above. This functional form must satisfy three basic conditions: (1) when there is no learning, $\alpha_{2}^{L H}=\alpha_{2}^{H H}=\alpha_{2}^{H L}=\alpha_{1}$, and $\left(\alpha_{2}^{S}-\right.$ $\left.\alpha_{2}^{v}\right)=0$, thus $f(0, \gamma)=0$; (2) when there is maximum learning, $\alpha_{2}^{L H}=\alpha_{2}^{H H}=\alpha_{2}^{H L}=1 / 2$, and $\left(\alpha_{2}^{S}-\right.$ 
$\left.\alpha_{2}^{v}\right)=0$, thus $f(1, \gamma)=0$; (3) in terms of $\gamma$, the functional form must satisfy $\frac{\partial f(\lambda, \gamma)}{\partial \gamma}<0 .{ }^{10}$ In particular, we propose the following specification:

$$
f(\lambda, \gamma)=\lambda(1-\lambda)(a-b \gamma) \quad(G L-3)
$$

with $0<b<a<1$ for firm $h$ 's strategies in condition $G L-1$ and $0<a<b<1$ for firm l's strategies in condition $G L-2$.

Figure 2 plots equation $G L-3$ for both firms for different learning rates. ${ }^{11}$ First, we note that, as mentioned above, in the presence of learning, firm $h$ faces a larger opportunity cost from accommodating firm $l$ because its relative capability erodes. In addition, as the learning rate increases from 0.25 to 0.5 , firm $h$ 's opportunity cost also increases regardless of the relative value of both markets. ${ }^{12}$ On the other hand, the effect for firm $l$ depends on the relative value of the two markets; when market value of $L$ cost is small, firm $l$ faces increasing opportunity costs of not entering in the market with larger value. As the two markets become more similar, the opportunity cost transforms into a benefit and firm $l$ prefers to locate alone in the low value market. ${ }^{13}$

\footnotetext{
${ }^{10}$ We impose this condition for the following reason: In GL-1, we compared $\alpha_{2}^{L H}$ with $\alpha_{2}^{H H}$. When firm $h$ accommodates firm $l$ and enters the low-value market, its learning opportunities depend on how small is the lowvalue market, that is, on $\gamma$. As $\gamma$ decreases, that is, as the low-value market's profitability decreases, firm $h$ learns relatively less, while firm $l$ learns relatively more so that $\alpha_{2}^{L H}$ increases, and $\alpha_{2}^{L H}-\alpha_{2}^{H H}$ increases. In GL-2, we compared $\alpha_{2}^{H H}$ with $\alpha_{2}^{H L}$. As per the argument above, when firm $l$ accommodates firm $h$ and enters the low-value market it will learn relatively less when the low-value market's profitability decreases. Thus, as $\gamma$ decreases, $\alpha_{2}^{H L}$ decreases, and so does $\alpha_{2}^{H H}-\alpha_{2}^{H L}$. In both cases, a decrease in $\gamma$ increases $\left(\alpha_{2}^{S}-\alpha_{2}^{v}\right)$, so $\frac{\partial f(\lambda, \gamma)}{\partial \gamma}<0$.

${ }^{11}$ The additional parameters are $a=0.15$ and $b=0.1$ for firm $h ; a=0.1$ and $b=0.15$ for firm $l$.

${ }^{12} \mathrm{We}$ note, however, that a further increase in the learning rate has the opposite effect on firm $h$ 's opportunity cost. In fact, when the learning rate is equal to 1 , firms achieve equal capabilities regardless of their first-period location choices, as in the no-learning scenario, so that the opportunity cost generated by learning disappears. This is not depicted in the figure.

${ }^{13}$ As in firm $h$ 's case, an increase in the rate of learning amplifies the opportunity cost/benefit of learning up to a point. Further increases dampen the opportunity cost/benefit of learning until, when the learning rate becomes equal to 1 , it is erased completely.
} 
Figure 2: Opportunity costs/benefits for firms $h$ and $l$. Global-learning scenario with learning rates $(\lambda)$ equal to 0.5 and 0.25

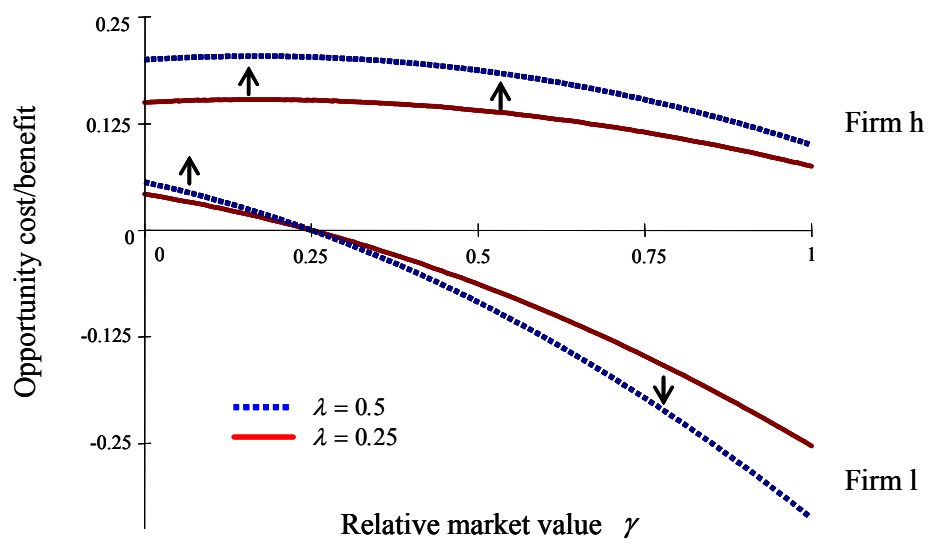

The final equilibrium strategies are detailed in Table 4 and plotted in the $\gamma-\alpha$ parameter space in Figure 3. In the presence of learning, firm $h$ is behaving more aggressively to prevent an erosion of its relative capability, regardless of the relative market value differential or the relative capability gap. As a result, it would adopt a collocate or marginalize strategy more often and an accommodate strategy less often. This aggressive behavior increases for small to medium learning rates (specifically for $\lambda \in$ $(0,0.5])$, but becomes less pronounced as the learning rate increases. By contrast, the impact of learning on firm $l$ 's strategy is more complex. First, when markets are relatively similar in value, firm $l$ becomes less aggressive in entering the high-value market first simply due to the fact that firm $h$ becomes more aggressive in doing so. However, if relative capabilities are similar, firm $l$ becomes less aggressive and is marginalized even when differences in market values are relatively large. This is because even though monopoly profits in a smaller market are lower, being a monopoly in the small market still offers better learning opportunities. On the other hand, when capability differentials between firms are large, firm $l$ becomes more aggressive and collocates more often because even though it gives up monopoly profits, it prevents its relative capability from eroding too much (which would happen if it allowed firm $h$ to be a monopolist in a much larger market). For small to medium learning rates (specifically for $\lambda \in(0,0.5])$, these effects are amplified, but they decrease as learning rates increase (specifically for $\lambda \in(0.5,1])$. 
Figure 3: Equilibrium strategies: Global-learning scenario

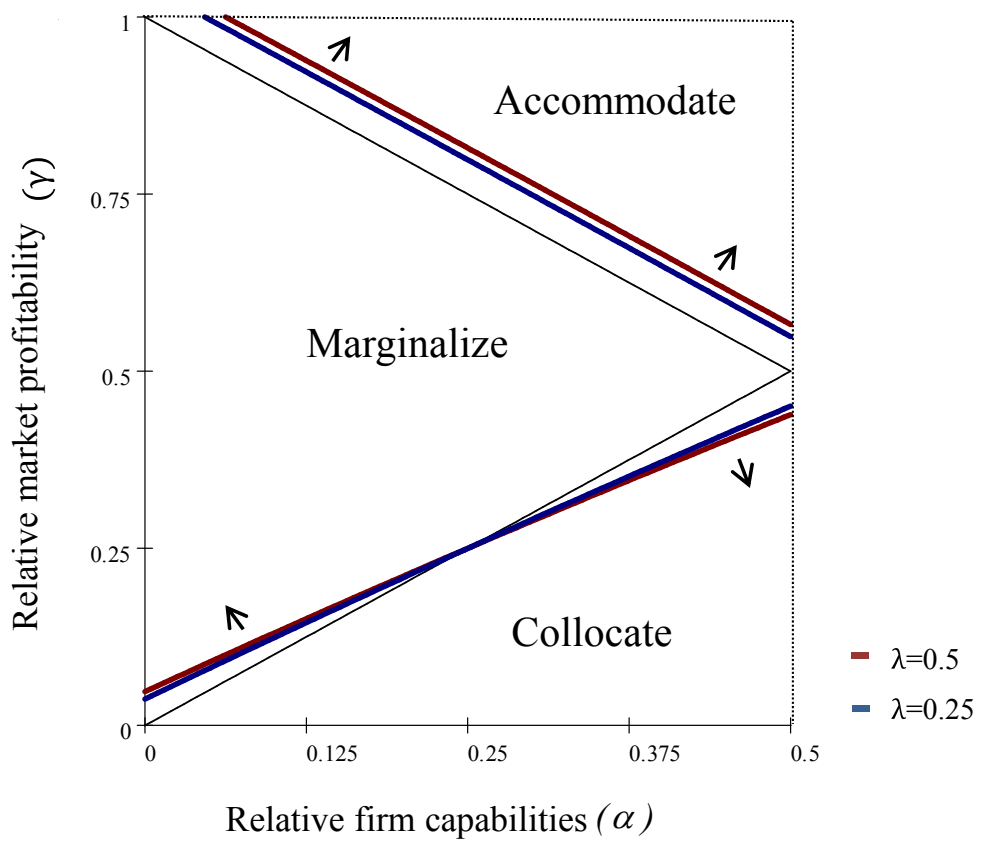

Note that the more capable firm behaves more aggressively regardless of the relative market value differential or the relative capability gap: it is less likely to give up a first-mover status in the more attractive market. As a result, it would adopt a collocate or marginalize strategy more often and seldom adopt an accommodate strategy. The less capable firm is more likely to enter the less attractive market first not only because it is more likely to be marginalized by the more capable firm, but also because it reduces its competitive gap by being a monopolist in that market when the market-value differential and the capability gap are small.

Table 4: Equilibrium Strategies. Global-learning scenario, no exit

\begin{tabular}{|c|c|c|}
\hline Parameters & Strategy & Type \\
\hline$\left(1-\alpha_{1}\right)+\left(\alpha_{2}^{L H}-\alpha_{2}^{H H}\right)(1+\gamma)<\gamma$ & $s_{h}=\{(L, \varnothing),(L, H)\}$ & Accommodate \\
& $s_{l}=\{(\varnothing, H),(L, H)\}$ & \\
\hline$\alpha_{1}+\left(\alpha_{2}^{H H}-\alpha_{2}^{H L}\right)(1+\gamma)<\gamma<$ & $s_{h}=\{(\varnothing, H),(L, H)\}$ & Marginalize \\
$\left(1-\alpha_{1}\right)+\left(\alpha_{2}^{L H}-\alpha_{2}^{H H}\right)(1+\gamma)$ & $s_{l}=\{(L, \varnothing),(L, H)\}$ & \\
\hline$\gamma<\alpha_{1}+\left(\alpha_{2}^{H H}-\alpha_{2}^{H L}\right)(1+\gamma)$ & $s_{h}=\{(\varnothing, H),(L, H)\}$ & Co-locate \\
& $s_{l}=\{(\varnothing, H),(L, H)\}$ & \\
\hline
\end{tabular}




\section{Local learning}

Similar to the global-learning case, the strategies followed in the first period determine the secondperiod relative firm capabilities under a local-learning scenario. However, under local learning the cumulative experience gained by firm $i$ in market $j$ changes its second-period absolute capability only in market $j$. As a result, although as in the global learning scenario, $\alpha_{j 2}^{H L} \neq \alpha_{j 2}^{L H} \neq \alpha_{j 2}^{H H} \neq \alpha_{1}$, in the local learning scenario $\alpha_{L 2}^{S} \neq \alpha_{H 2}^{S}$ for all strategies $s$.

As before, we solve the game by backward induction. Thus, we assume, first, that firm $l$ enters the high-value market in the first period (strategy $s_{l 1}=(\emptyset, H)$ ). Then, the more capable firm $h$ must decide whether to avoid and accommodate the less capable firm $l$ (strategy $s_{h 1}=(L, \emptyset)$ ) or collocate with it (strategy $\left.s_{h 1}=(\varnothing, H)\right)$. Table 5 introduces these two options with their associated profits.

Table 5: Moves for firm $h$ when firm $l$ enters high-value market $H$. Local learning scenario with no exit.

\begin{tabular}{|c|c|c|l|}
\hline & Strategies $\mathrm{t}=1$ & Strategies $\mathrm{t}=2$ & \multicolumn{1}{|c|}{ Profits $\mathrm{t}=2$} \\
\hline Avoid & $s_{h 1}=(L, \varnothing)$ & $s_{h 2}=(L, H)$ & $\pi_{h 2}=\left(1-\alpha_{H 2}^{L H}\right) V^{H}+\left(1-\alpha_{L 2}^{L H}\right) V^{L}$ \\
& $s_{l 1}=(\varnothing, H)$ & $s_{l 2}=(L, H)$ & $\pi_{l 2}=\alpha_{H 2}^{L H} V^{H}+\alpha_{L 2}^{L H} V^{L}$ \\
\hline Collocate & $s_{h 1}=(\emptyset, H)$ & $s_{h 2}=(L, H)$ & $\pi_{h 2}=\left(1-\alpha_{H 2}^{H H}\right) V^{H}+\left(1-\alpha_{1}\right) V^{L}$ \\
& $s_{l 1}=(\varnothing, H)$ & $s_{l 2}=(L, H)$ & $\pi_{l 2}=\alpha_{H 2}^{H H} V^{H}+\alpha_{1} V^{L}$ \\
\hline
\end{tabular}

Given $s_{l 1}=(\varnothing, H)$, firm $h$ 's decision of whether to collocate initially depends on the comparison between its total profits from accommodating firm $l, V^{L}+\left(1-\alpha_{H 2}^{L H}\right) V^{H}+\left(1-\alpha_{L 2}^{L H}\right) V^{L}$, and its total profits under sequential collocation, $\left(1-\alpha_{1}\right) V^{H}+\left(1-\alpha_{H 2}^{H H}\right) V^{H}+\left(1-\alpha_{1}\right) V^{L}$. Specifically, firm $h$ avoids and accommodates firm $l$ when

$$
\gamma>\left(1-\alpha_{1}\right)+\left(\alpha_{H 2}^{L H}-\alpha_{H 2}^{H H}\right)+\left(\alpha_{L 2}^{L H}-\alpha_{1}\right) \gamma \quad(L L-1)
$$

Compared to the equivalent condition in the no-learning scenario $(N L-1)$, two extra terms in expression $L L-1$ capture the effect of local learning on $h$ 's strategy: the opportunity costs of absence from $H$ and the entrenchment benefits of early presence in $L$. 
The first term in $L L-1, \alpha_{H 2}^{L H}-\alpha_{H 2}^{H H}$, represents firm $h$ 's opportunity cost of allowing firm $l$ to improve its relative position in $H$. This term, similar to the one in equation $(G L-1)$ for global learning, is always positive because firm $l$ learns more in monopoly than in duopoly and because firm $h$ does not learn at all when it is not present in a market; therefore, $\alpha_{H 2}^{L H}>\alpha_{H 2}^{H H}$. This causes firm $h$ to behave more aggressively and collocate early in the high-value market. The second term, $\alpha_{L 2}^{L H}-\alpha_{1}$, is in contrast to the corresponding term in the global learning condition $G L-1$, in that, instead of capturing an opportunity cost, it captures the benefit to firm $h$ when it entrenches in the low-value market $L$ and increases its competitive position there. In fact, this term is always negative because, even for very low-value markets (when $\gamma$ is close to 0), firm $h$ improves from past experience in market $L$ and $\alpha_{L 2}^{L H}<\alpha_{1}$. Note however that the overall effect is always positive, that is, $\left(1-\alpha_{1}\right)+\left(\alpha_{H 2}^{L H}-\alpha_{H 2}^{H H}\right)+\left(\alpha_{L 2}^{L H}-\alpha_{1}\right) \gamma>0$, because, even when markets are of equal size $(\gamma=1)$ and $h$ 's entrenchment benefit is maximized, $h$ 's capability in market $H$ erodes more than its capability in market $L$ improves, that is, $\left(\alpha_{H 2}^{L H}-\alpha_{H 2}^{H H}\right)>-\left(\alpha_{1}-\alpha_{L 2}^{L H}\right){ }^{14}$ As a consequence, firm $h$ becomes more aggressive than in the no-learning scenario, in order to avoid any opportunity cost.

We now analyze firm $l$ 's strategy when firm $h$ expands initially to the high value market $H$. As in previous cases, firm $l$ faces two alternatives: avoid firm $h$ by locating in the low-value market (strategy $\left.s_{l 1}=(L, \varnothing)\right)$ or collocate by entering the high-value market (strategy $s_{l 1}=(\varnothing, H)$ ). Table 6 summarizes these options with their associated profits.

\footnotetext{
${ }^{14}$ One way to motivate this assertion is to consider the same simple Cournot model mentioned in footnote 9 , and the particular functional form for $\alpha$, namely $\alpha=\left(\frac{1}{2} * \frac{c_{h}}{c_{i}}\right)$, with $c_{h}<c_{l}$, in accordance with the idea that firm $h$ has a higher ability to capture market value, which is reflected in a lower marginal cost. In addition, by assuming that firms produce a high enough quantity to reach the lowest possible marginal cost, which we denote with $\underline{\mathrm{c}}$, in the second period in the market they are present in, we have $\alpha_{H 2}^{L H}-\alpha_{H 2}^{H H}=\frac{1}{2}\left(\frac{c_{h}}{c}-\frac{c}{c}\right)>0$, and $\alpha_{L 2}^{L H}-\alpha_{1}=$ $\frac{1}{2}\left(\frac{\underline{c}}{c_{l}}-\frac{c_{h}}{c_{l}}\right)<0$. However, $\left(\alpha_{H 2}^{L H}-\alpha_{H 2}^{H H}\right)+\left(\alpha_{L 2}^{L H}-\alpha_{1}\right)=\frac{1}{2}\left(\frac{c_{h}}{\underline{c}}-\frac{\underline{c}}{\underline{c}}\right)-\frac{1}{2}\left(\frac{c_{h}}{c_{l}}-\frac{\underline{c}}{c_{l}}\right)=\frac{1}{2} \frac{\left(c_{h}-\underline{c}\right)\left(c_{l}-\underline{c}\right)}{\underline{\underline{c}} c_{l}}>0$. In other words, when the learning process is attached to a downward sloping curve (such as a traditional learning curve) and when the markets are identical, firm $l$ gains more than firm $h$ from the same quantity produced, given their initial conditions, because its cost reduction is larger.
} 
Table 6: Moves for firm $l$ when firm $h$ enters high-value market $H$. Global-learning scenario with no exit.

\begin{tabular}{|c|l|l|c|}
\hline & Strategies $\mathrm{t}=1$ & Strategies $\mathrm{t}=2$ & Profits $\mathrm{t}=2$ \\
\hline Avoid & $s_{h 1}=(\varnothing, H)$ & $s_{h 2}=(L, H)$ & $\pi_{h 2}=\left(1-\alpha_{H 2}^{H L}\right) V^{H}+\left(1-\alpha_{L 2}^{H L}\right) V^{L}$ \\
& $s_{l 1}=(L, \emptyset)$ & $s_{l 2}=(L, H)$ & $\pi_{l 2}=\alpha_{H 2}^{H L} V^{H}+\alpha_{L 2}^{H L} V^{L}$ \\
\hline Collocate & $s_{h 1}=(\varnothing, H)$ & $s_{h 2}=(L, H)$ & $\pi_{h 2}=\left(1-\alpha_{H 2}^{H H}\right) V^{H}+\left(1-\alpha_{1}\right) V^{L}$ \\
& $s_{l 1}=(\varnothing, H)$ & $s_{l 2}=(L, H)$ & $\pi_{l 2}=\alpha_{H 2}^{H H} V^{H}+\alpha_{1} V^{L}$ \\
\hline
\end{tabular}

As before, firm $l$ will avoid firm $h$ when the benefit from being a monopolist in the low-value market is greater than the opportunity cost of sharing the high-value market. Specifically, firm $l$ avoids firm $\mathrm{h}$ if $V^{L}+\alpha_{H 2}^{H L} V^{H}+\alpha_{L 2}^{H L} V^{L}>\alpha_{1} V^{H}+\alpha_{H 2}^{H H} V^{H}+\alpha_{1} V^{L}$ or alternatively if

$$
\gamma>\alpha_{1}+\left(\alpha_{H 2}^{H H}-\alpha_{H 2}^{H L}\right)+\left(\alpha_{1}-\alpha_{L 2}^{H L}\right) \gamma
$$

As in the case of firm $h$, firm $l$ also faces opportunity costs (the positive term $\alpha_{H 2}^{H H}-\alpha_{H 2}^{H L}$ ) and entrenchment benefits (the negative term $\alpha_{1}-\alpha_{L 2}^{H L}$ ). By allowing itself to be marginalized in the lowvalue market, firm l's relative capability in the high-value market erodes because firm $h$ learns more as a monopolist than as a duopolist in $H$ and because firm $l$ does not learn at all when it is not present in a market, thus $\alpha_{H 2}^{H H}-\alpha_{H 2}^{H L}>0$. On the other hand, by entrenching in the low-value market, firm $l$ catches up with, or even overtakes, firm $h$ in that market because $\alpha_{1}<\alpha_{L 2}^{H L}$. Note that, contrary to the case of firm $h$, the entrenchment benefits may be larger than the opportunity costs when market $L$ is large (when $\gamma=1$ ), prompting firm $l$ to behave less aggressively than in the no-learning scenario. ${ }^{15}$ The final outcome of these countervailing forces will therefore depend on the magnitudes of the opportunity cost and entrenchment benefit, which are determined by the relative market value $\gamma$ and by the speed of learning $\lambda$.

${ }^{15}$ As in footnote 14 , let $\alpha=\left(\frac{1}{2} * \frac{c_{h}}{c_{i}}\right)$. By continuing to assume that firms produce a high enough quantity to reach the lowest possible marginal cost in the second period in the market they are present in, we have $\alpha_{H 2}^{H H}-\alpha_{H 2}^{H L}=$ $\frac{1}{2}\left(\frac{\underline{c}}{\underline{c}}-\frac{\underline{c}}{c_{l}}\right)>0$, and $\alpha_{1}-\alpha_{L 2}^{H L}=\frac{1}{2}\left(\frac{c_{h}}{c_{l}}-\frac{c_{h}}{\underline{c}}\right)<0$. However, $\left(\alpha_{H 2}^{H H}-\alpha_{H 2}^{H L}\right)+\left(\alpha_{1}-\alpha_{L 2}^{H L}\right)=\frac{1}{2}\left(\frac{\underline{c}}{\underline{c}}-\frac{\underline{c}}{c_{l}}\right)-$ $\frac{1}{2}\left(\frac{c_{h}}{\underline{c}}-\frac{c_{h}}{c_{l}}\right)=\frac{1}{2} \frac{\left(c_{l}-\underline{c}\right)\left(\underline{c}-c_{h}\right)}{\underline{c} c_{l}}<0$. The same reasoning is behind this result: when the markets are identical, firm $l$ gains more than firm $h$ from the same quantity produced, given their initial conditions, because its cost reduction is larger. 
To illustrate further how these terms (the opportunity cost of not being in a location and the entrenchment benefit of entering there early) affect expansion strategies and firms' behavior under local learning, we now introduce functional forms for opportunity costs, $f(\lambda)$, and entrenchment benefits, $g(\lambda, \gamma)$, that preserve the intuitive behavior described above.

We start with opportunity costs. Note that the opportunity cost terms, $\alpha_{H 2}^{L H}-\alpha_{H 2}^{H H}$ in $L L-1$ and $\alpha_{H 2}^{H H}-\alpha_{H 2}^{H L}$ in $L L-2$, do not depend on relative market values $(\gamma)$ because, in the absence of spillovers across markets, only experience in market $H$ lowers costs and affects relative capabilities in that market. Therefore the functional form depends only on the speed of learning $\lambda$. When there is no learning, $\lambda=0$, $\alpha_{j 2}^{H L}=\alpha_{j 2}^{H H}=\alpha_{j 2}^{L H}=\alpha_{1}$, so $f(0)=0$. When learning is at its maximum, $\lambda=1$, firm $l$ closes its gap with firm $h$ in market $H$, so $\alpha_{H 2}^{L H}=\alpha_{H 2}^{H H} \approx \frac{1}{2}$ for $L L-1$, or firm l's relative capabilities erode in market $H$, so $\alpha_{H 2}^{H H} \approx \frac{1}{2} \geq \alpha_{H 2}^{L H}$. In both cases, $f(1)>0$.

Entrenchment benefits depend on both relative market value and learning speed, thus $g()=.g(\lambda, \gamma)$. When there is no learning, $g(0, \gamma)=0$ because $\alpha_{H 2}^{L H}=\alpha_{1}$ and $\alpha_{1}=\alpha_{L 2}^{H L}$; when learning is at its maximum, $g(1, \gamma)<0$ because $\alpha_{H 2}^{L H}<\alpha_{1}$ and $\alpha_{1}<\alpha_{L 2}^{H L}$.

In particular, the functional forms

$$
f(\lambda)=a \lambda \text { and } g(\lambda, \gamma)=-b \gamma \lambda \quad(L L-3)
$$

with $0<b<a<1 / 2$ for firm $h$ 's strategies in condition $L L-1$ and $0<a<b<1 / 2$ for firm $l$ 's strategies in condition $L L-2$, satisfy all the conditions above. Figure 4 plots the values of absence opportunity costs and entrenchment benefits for firms $h$ (left panel) and firm $l$ (right panel).

Figure 5 plots the net opportunity cost against relative market value for two learning rates: 0.25 and 0.5. In the presence of learning, firm $h$ behaves more aggressively to prevent an erosion of its relative capability in the high-value market, regardless of the relative market value differential or the relative capability gap. Moreover, higher learning rates increase firm $h$ 's opportunity cost more than the benefit 
from entrenching, shifting upwards the net opportunity cost for firm $h$ for all levels of relative market value. ${ }^{16}$ Therefore, firm $h$ becomes more aggressive, i.e., it is less likely to accommodate, and more likely to marginalize or collocate with, the less capable firm.

Figure 4: Opportunity costs and entrenchment benefits for firms $h$ and $l$. Local-learning scenario with $\lambda=0.25$.

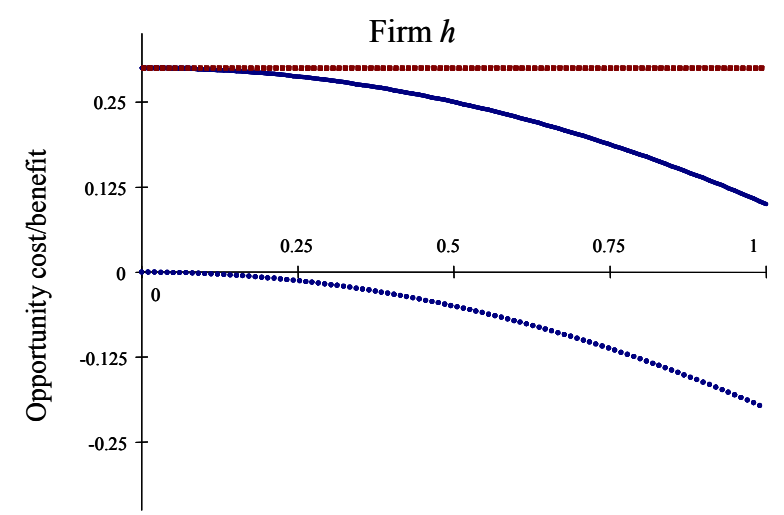

Relative market value $\gamma$

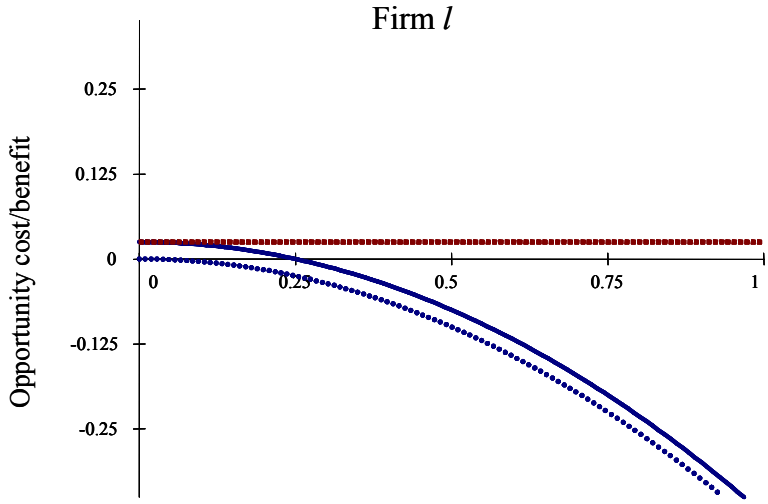

Relative market value $\gamma$

.... Opportunity cost $\quad \ldots .$. Entrenchment benefit $\quad$ - Total effect

Figure 5: Opportunity costs/benefits for firms $h$ and 1. Local-learning scenario with learning rates $(\lambda)$ equal to 0.5 and 0.25

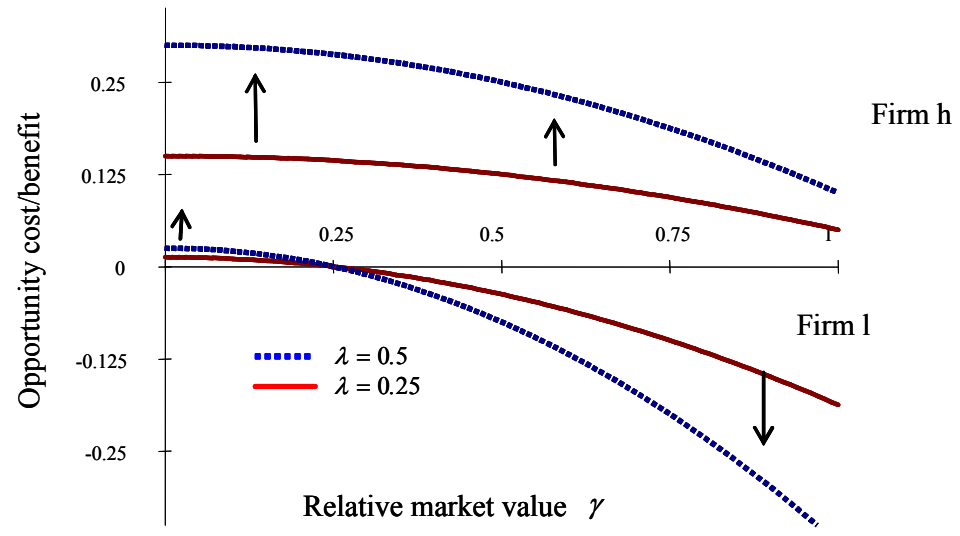

When markets are relatively similar in value, firm $l$ becomes less aggressive in entering the highvalue market simply because firm $h$ becomes more aggressive in doing so. However, if relative

\footnotetext{
${ }^{16}$ This effect becomes less pronounced as the learning rate increases because any advantage gained in the first period is eroded and firms' first-period location choices depend solely on first-period profits, as in the no-learning scenario.
} 
capabilities are similar, firm $l$ becomes less aggressive and is marginalized even when differences in market values are relatively large, because its entrenchment benefit in that low-value market are higher than the opportunity cost of not being present in the high-value market. On the other hand, when capability differentials between the firms are large, firm $l$ becomes more aggressive and collocates more often because, even though it gives up monopoly profits, it prevents its relative capability from eroding too much (as would happen by allowing firm $h$ to be a monopolist in a much larger market). ${ }^{17}$

The final equilibrium strategies are detailed in Table 7, while Figure 6 shows how the areas for each strategy presented in Table 7 change as learning rates increase. As either markets or firms become more dissimilar, both firms benefit less from accommodate strategies and favor marginalize strategies (for larger differences in firm capabilities) and, to a lesser extent, collocate strategies (for smaller differences in firm capabilities). The main driver of this behavior is the tradeoff between (a) the entrenchment benefit from being a monopolist in the low-value market and gaining a higher second-period relative position in that market, and (b) the opportunity cost of sharing the high-value market and letting a rival gain a higher second-period relative position in it. Comparing Figure 4 and Figure 6 reveals that local learning promotes more marginalizing, and less collocating, than global learning.

Table 7: Equilibrium Strategies. Local-learning scenario, no exit

\begin{tabular}{|c|c|c|}
\hline Parameters & Strategy & Type \\
\hline$\left(1-\alpha_{1}\right)+\left(\alpha_{2 H}^{L H}-\alpha_{2 H}^{H H}\right)+\left(\alpha_{2 L}^{L H}-\alpha_{1}\right) \gamma<\gamma$ & $s_{h}=\{(L, \varnothing),(L, H)\}$ & Accommodate \\
\hline$\alpha_{1}+\left(\alpha_{2 H}^{H H}-\alpha_{2 H}^{H L}\right)+\left(\alpha_{1}-\alpha_{2 L}^{H L}\right) \gamma$ & $s_{h}=\{(\varnothing, H),(L, H)\}$ & \\
$<\gamma<$ & $s_{l}=\{(L, \varnothing),(L, H)\}$ & \\
$\left(1-\alpha_{1}\right)+\left(\alpha_{2 H}^{L H}-\alpha_{2 H}^{H H}\right)+\left(\alpha_{2 L}^{L H}-\alpha_{1}\right) \gamma$ & & \\
\hline$\gamma<\alpha_{1}+\left(\alpha_{2 H}^{H H}-\alpha_{2 H}^{H L}\right)+\left(\alpha_{1}-\alpha_{2 L}^{H L}\right) \gamma$ & $s_{h}=\{(\varnothing, H),(L, H)\}$ & Collocate \\
& $s_{l}=\{(\varnothing, H),(L, H)\}$ & \\
\hline
\end{tabular}

\footnotetext{
${ }^{17}$ These effects are amplified up to a certain speed of learning but decrease as learning rates become very high. After that point, any advantage gained in the first period is eroded very quickly in the second period as the competitor quickly catches up.
} 
Figure 6: Opportunity costs/benefits for firms $h$ and 1 . Local-learning scenario with learning rates $(\lambda)$ equal to 0.5 and 0.25

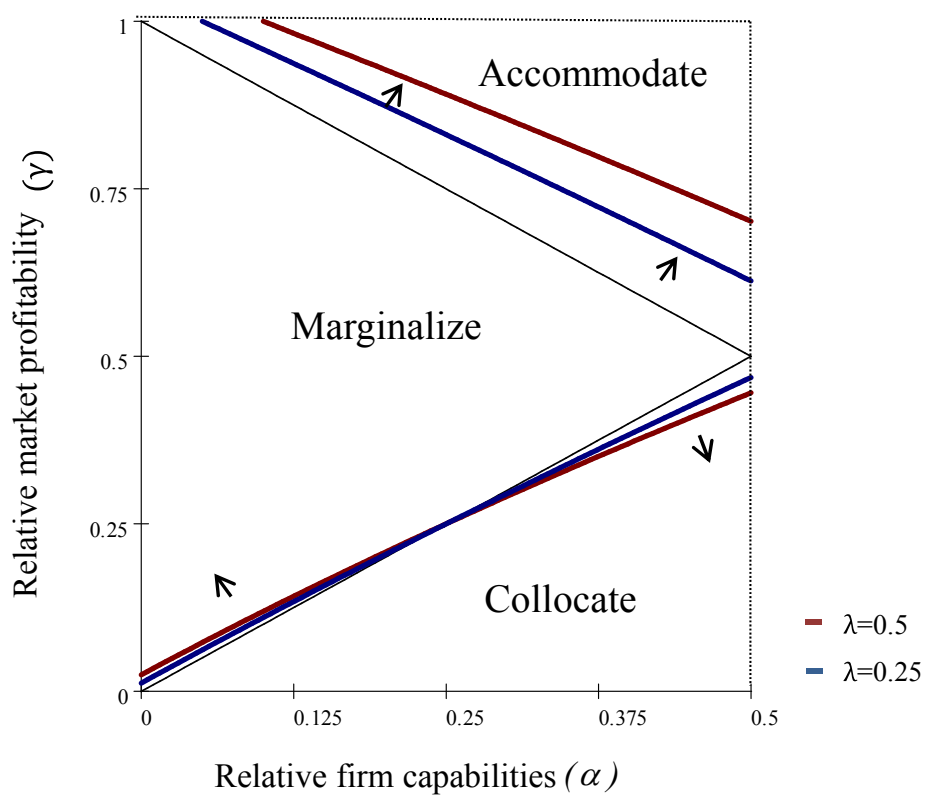

\section{Discussion and Conclusions}

This paper explores how strategic interaction affects the geographic expansion of heterogeneous firms across time and markets. Specifically, we build a model in which two firms that differ in their capabilities enter sequentially into two markets with different potentials for profit. The model is solved using game theory under three learning scenarios that capture the ability of a firm to transfer its capabilities across markets: no learning, local learning, and global learning. Three equilibrium strategies emerge: accommodate, marginalize, and collocate. We identify how these strategies are more or less likely to emerge depending on three parameters: initial relative firm capabilities, relative market profitability, and learning rates.

Our approach draws on original work in international business (Knickerbrocker, 1973; Flower, 1976; Hymer, 1976; Yu \& Ito, 1988) that introduced strategic interaction as a trigger for firms expanding abroad. We bring modeling tools from IO that were not available at that time, allowing us to better delineate the effect of strategic interaction on location choices. We also draw from the location literature (Shaver \& Flyer, 2001; Alcacer \& Chung, 2010) that explores what strategic interactions firms consider 
when deciding to locate in a cluster, and from the international strategy literature that identifies learning scenarios among multinationals based on their overall MNE strategy (Bartlett \& Ghoshal, 1989).

The model provides several testable predictions. First, collocation is less likely to occur among firms with similar capabilities or when geographic markets are similarly attractive. Second, when markets are similar in size, a less capable firm will initially be marginalized to peripheral markets. This marginalize strategy becomes more likely as learning changes: it is the most likely with global learning, less likely with local learning, and the least likely when there is no learning. Third, a more capable firm becomes more aggressive when learning exists (with its highest point under global learning) or when the learning rate is higher. Results from our model suggest that MNEs' location decisions look substantially different when strategic interaction is included.

More importantly, the model crystalizes two forces that determine strategic interaction among firms in the geographic space: the opportunity costs of not entering a market - a force that encourages contemporaneous entry — and the benefits of entrenchment by entering early — a force that encourages firms to delay collocation. Including both forces in future research will provide a richer framework that better describes actual location patterns across time and markets.

This paper offers several contributions to our understanding of location strategies. First, we are reminded that strategic interaction affects how firms locate. The presence or absence of firms in a location exerts centrifugal and centripetal forces that influence the location's attractiveness. In the same way that Ghemawat (2001) introduced multidimensional distance between home and host markets as a lens affecting a location's attractiveness, our work suggests another lens: strategic interaction. Importantly, this lens helps us to explain not only one location decision at a point in time, but also a set of location decisions across time. After all, location decisions are not static and isolated decisions related to specific geographic markets; they are events linked across time and geography. For empirical work, overlooking strategic interaction amounts to an omitted variable problem that may produce biased estimates for coefficients associated with location traits. 
Second, our work creates a most-needed link between strategy and international business scholarship. Earlier work in international business (e.g., Chang, 1995) tries to associate firm capability and learning with entry decisions, but there is no location choice involved in the analysis. Delios and Henisz (2003) analyze location choice decisions based on the learning of institutional environments, but there is no interaction between the decisions of rival firms. By adding concepts familiar to strategy scholars, such as competitive advantage and strategic interaction, we underline that a firms' operations abroad are also an important source of sustainable competitive advantage in oligopolistic competition.

Third, our paper offers an alternative explanation, grounded in economic principles, to the "bunching" behavior widely reported in previous research (Lieberman \& Asaba, 2006). Even in a model that does not include any benefit from clustering, and does not assume unique market resources, simultaneous entries and "imitative" behavior can emerge from strategic interaction. In other words, instead of explaining collocation as a function of agglomeration benefits (Marshall, 1892; David \& Rosenbloom, 1990) or mimetic behavior (Lieberman \& Asaba, 2006) due to asymmetric information or uncertainty (Henisz \& Delios, 2001), our paper provides an alternative explanation based solely on strategic interaction and competition. In addition, for the multimarket contact literature, the paper provides a theoretical framework for understanding the mechanisms and constraints emerging from competition in product markets that regulate the number of contacts between firms across markets.

Fourth, the level of abstraction in the model also allows us to extend its predictions beyond entry in geographic markets to, for instance, entry into new product markets. ${ }^{18}$ In this new context, learning scenarios represent the ability of firms to exploit synergies across industries when firms diversify; learning rates map to levels of relatedness across industries.

\footnotetext{
${ }^{18}$ The applicability of spatial models is not a unique feature of our model. The modeling technique that considers demand along a continuous line of product attributes, a building block of most models in industrial organization and marketing, comes from the Hotelling model that originally looked at where to locate a stand on a long beach.
} 
For managers, this paper illustrates different ways firms can use location choices across time and geographic markets as a tool to enhance or preserve their competitive position within an industry. In that sense it reveals the importance of further research on geographic diversification and its impact on value creation.

Following the path of formal modeling has advantages and disadvantages. On the positive side, a formal model allows us to explore the complex relationship between firm heterogeneity, market heterogeneity, and spatial strategic interaction in a parsimonious and unequivocal way. However, to parsimoniously undertake a complex phenomenon, we needed to simplify the model's elements by reducing multiple location traits into the concept of market value. Although we do not elaborate on what drives market value, we believe that the very rich empirical literature in this area offers a comprehensive list. Simplification also means that our model doesn't support two key ideas in the location literature. First, although location attractiveness varies by an MNE's country of origin (Ghemawat, 2001), we do not allow that distance to vary by firm. In other words, we assume that all firms are expanding from a similar home country. Second, this assumption doesn't allow us to incorporate home market advantages. Future work should extend our model to incorporate heterogeneity in firms' home markets. We would expect these sources of heterogeneity to create protective barriers, diminish collocation, and curb aggressive expansion strategies.

Our modeling of firm heterogeneity is richer, which allows us to capture a few important traits. Using differences in marginal costs to capture competitive advantage is more general than one might assume. For example, advantages linked to a higher willingness-to-pay have effects that are symmetric to advantages linked to lowering costs. Our approach, which equates advantages from learning with advantages from lowering costs, mimics an approach that equates advantages from learning with inducing a higher willingness-to-pay (by, for example, creating new products). This point is especially important given that the idea of firms moving overseas to expand their knowledge bases (Kogut and Chang, 1991) has played a prominent role in the location literature for the past 15 years. 
One area for future research, and an important limitation of our model, is the decomposition of the value chain across locations. In our model, firms produce and sell in the same market and there is no role for separating production from sales (or R\&D). In other words, our model is more appropriate to international strategies in industries in which production and sales are local, such as wireless operators, fast food, banking, and, more generally, services. This obvious limitation is not as binding as one might think, however, because it is also true that MNEs have regional strategies in which they produce in one country and export to a few proximate markets. If the unit of analysis is adjusted from the country level to the region level, our model should still provide valuable insights. A firm incurs initial costs to sell in markets just as it does to produce in markets, and learning-by-doing applies in both cases as the firm becomes more knowledgeable. If a company has production and sales facilities in a given country, one could assume some cost advantage over competitors, captured by differential marginal costs. In other words, the model may fit more settings than the paper explores explicitly.

Finally, our model focuses on one type of strategic interaction: pure competition in the product market. Other forms of strategic interaction also need development, such as collocation to soften competition through price collusion, as suggested by Ghemwat \& Thomas (2008) among others. Despite these limitations, our models make clear that scholars interested in location decisions by MNEs must look beyond location traits and firm traits to consider the complex and critical influence of strategic interaction. 


\section{Bibliography}

Alcacer, Juan, and Wilbur Chung. 2010. Location Strategies for Agglomeration Economies. Harvard Business School Working Paper No. 10-071, Boston, MA.

Bartlett, Christopher A., and Sumantra Ghoshal. 1989. Managing Across Borders: The Transnational Solution. Boston, MA: Harvard Business Press.

Baum, Joel A. C., and Stephen J. Mezias. 1992. Localized Competition and Organizational Failure in the Manhattan Hotel Industry, 1898-1990. Administrative Science Quarterly, 37(4): 580-604.

Berry, Steven T. 1992. Estimation of a Model of Entry in the Airline Industry. Econometrica, 60(4): 889918.

Bresnahan, Timothy F., and Peter C. Reiss. 1991. Entry and Competition in Concentrated Markets. Journal of Political Economy, 99(5): 977-1010.

Carlton, Dennis W. 1983. The Location and Employment Choices of New Firms: An Econometric Model with Discrete and Continuous Endogenous Variables. Review of Economics and Statistics, 65(3): 440450 .

Caves, Richard. 1996. Multinational Enterprise and Economical Analysis. Cambridge: Cambridge University Press.

Chang, Sea Jin. 1995. International Expansion Strategy of Japanese Firms: Capability Building through Sequential Entry. Academy of Management Journal, 38(2): 383-407.

Coughlin, Cletus C., Joseph V. Terza, and Vachira Arromdee. 1991. State Characteristics and the Location of Foreign Direct Investment within the United States. Review of Economics and Statistics, 73: 675-683.

David, Paul, and Joshua Rosenbloom. 1990. Marshallian Factor Market Externalities and the Dynamics of Industrial Location. Journal of Urban Economics, 28: 349-70.

Delios, Andrew and Witold J. Henisz, 2003. Political Hazards, Experience and Sequential Entry Strategies: The International Expansion of Japanese Firms, 1980-1998. Strategic Management Journal, 24(11): 1153-1164.

Dunning, John H. 2009. Location and the multinational enterprise: John Dunning's thoughts on receiving the Journal of International Business Studies 2008 Decade Award. Journal of International Business Studies, 40(1): 20-34.

Epple, Dennis, Linda Argote, and Rukmini Devadas. 1991. Organizational Learning Curves: A method for investigating intra-plant transfer of knowledge acquired through learning by doing. Organization Science, 2(1): 58-70.

Ellickson, Bryan, and William R. Zame. 2005. A competitive model of economic geography. Economic Theory, 25(1): 89-103 
Flores, Ricardo G., and Ruth. V. Aguilera. 2007. Globalization and Location Choice: An Analysis of U.S. Multinational Firms in 1980 and 2000. Journal of International Business Studies, 38(7): 1187-1210.

Flowers, Edward B. 1976. Oligopolistic reaction in European and Canadian direct investment in the United States. Journal of International Business Studies, 7: 43-55.

Gimeno, Javier, Robert E. Hoskisson, Brent D. Beal, and William P. Wan. 2005. Explaining the Clustering of International Expansion Moves: A Critical Test in the U.S. Telecommunications Industry. Academy of Management Journal, 48(2): 297-319.

Ghemawat, Pankaj. 2001. Distance Still Matters: The Hard Reality of Global Expansion. Harvard Business Review, 79(8): 137-147

Ghemawat, Pankaj, and Catherine Thomas. 2008. Strategic Interaction Across Countries and Multinational Agglomeration. Management Science, 54(12): 1980-1996

Graham, Edward M. 1998. Market structure and the multinational enterprise: A game-theoretic approach. Journal of International Business Studies, 29(1): 67-83.

Head, Keith, John Ries, and Deborah Swenson. 1995. Agglomeration benefits and location choice: Evidence from Japanese manufacturing investments in the United States. Journal of International Economics, 38(3-4): 223-247.

Henisz, Witold J. 2000. The Institutional Environment for Multinational Investment. Journal of Law, Economics, and Organization, 16(2): 334-364.

Henisz, Witold J., and Andrew Delios. 2001. Uncertainty, Imitation, And Plant Location: Japanese Multinational Corporations, 1990-1996. Administrative Science Quarterly, 46(3): 443-75.

Hymer, Stephen. 1976. The international operations of national firms: a study of direct foreign investment. PhD Dissertation. (Published posthumously). Cambridge, MA: The MIT Press.

Knickerbrocker, Frederick. 1973. Oligopolistic Reaction and Multinational Enterprise. Cambridge, MA: Harvard University Press.

Kogut, Bruce, and Sea Jin Chang. 1991 Technological capabilities and Japanese foreign direct investment in the United States. Review of Economics and Statistics, 73(3): 401-413.

Krugman, Paul. 1991. Increasing Returns and Economic Geography. Journal of Political Economy, 99(3): 483-500.

Lieberman, Marvin, and Shigeru Asaba. 2006. Why Do Firms Imitate Each Other? Academy of Management Review, 31(2): 366-385.

Lee, Jeong-Yeon, and Edwin Mansfield. 1996. Intellectual Property Protection and U.S. Foreign Direct Investment. Review of Economics \& Statistics, (78)2: 181-185.

Marshall, Alfred. 1892. Elements of economics of industry. London: Macmillan. 
McCann, Philip, and Ram Mudambi. 2005. Analytical differences in the economics of geography: The case of the multinational firm. Environment and Planning A, 37(10): 1857-1876.

Spence, A. Michael. The Learning Curve and Competition. Bell Journal of Economics, 12(1): 49-70.

Shaver, Myles, and Frederick Flyer. 2000. Agglomeration economies, firm heterogeneity, and foreign direct investment in the United States. Strategic Management Journal, 21(12): 1175-1193.

Veugelers, Reinhilde. 1995. Strategic incentives for multinational operations. Managerial and Decision Economics, 16(1): 47-58.

Yu, Chwo-Ming J., and Kiyohiko Ito. 1988. Oligopolistic Reaction and Foreign Direct Investment: The Case of the U.S. Tire and Textiles Industries. Journal of International Business Studies, 19(3): 449-460.

Yu, Tieying, Mohan Subramaniam, and Albert A. Cannella, Jr. 2008. Rivalry Deterrence in International Markets: Contingencies Governing the Mutual Forbearance Hypothesis. Academy of Management Journal, 51(4): 768-795.

Wheeler, David, and Ashoka Mody. 1992. International Investment Location Decisions: The Case of U.S. Firms. Journal of International Economics, 33(1-2): 57-76. 